\title{
Effectiveness of a Group Educational Program on the Knowledge, Attitude, and Participation Approach of Mothers in the Sex Education of Preschool Children
}

\author{
Hadis Fatehi Pouladi ${ }^{1}$, Mahnaz Akbari Kamrani ${ }^{2}$, Mojgan JavadNoori ${ }^{3}$, Maliheh Farid ${ }^{4}$
}

\begin{abstract}
Background \& Aim: preschool students are vulnerable to sexual abuse due to not being taught the proper anatomical names for their body parts. Sex education reduces child sexual abuse if provided based on age and cultural conditions and presenting accurate and appropriate information about body parts and functions of each of them. On the other hand, education by knowledgeable parents will lead to both successful training and increased self-confidence in children. Therefore, parents, especially mothers, play a pivotal role in the sex education of children, which shows the necessity of sex education by parents. The present study aimed to assess the effectiveness of a group educational program on the knowledge, attitude, and participation approach of mothers in the sex education of preschool children.

Materials \& Methods: This randomized, controlled, parallel clinical trial was conducted on 58 mothers with children aged 3-7 years employed at Alborz University of Medical Sciences in Karaj, Iran during May-September 2018. The inclusion criteria were being an employee at Alborz University of Medical Sciences, being a mother (or a guardian) of a child, being literate, literacy in Farsi language, and lack of attending child sex education courses in the past six months. On the other hand, the exclusion criteria were unwillingness to participate in the study and lack of participation in training sessions. Data were collected using a demographic form (nine items: child's gender, child's age, the birth rank of the child, number of children, maternal marital status and level of education, and paternal marital status and level of education) and a researcher-made questionnaire with three sections on maternal knowledge, attitude, and participation in the sex education of preschool children. The items of researcher-made tools were extracted from resources and related tools in the specialized field of preschool sexual education and based on the opinion of experts. In six-nine-member groups, the participants in the intervention group received three training sessions (90 minutes each) with 10-day intervals. In the intervention group, group education of mothers was carried out by a trained midwife under the supervision of a team of reproductive health professionals using methods such as brainstorming, one-on-one expression of experiences, animation, and summarizing similar problems of mothers in the field of child sex education. Finally, active learning was done in groups. The content of the sessions was, as follows: In the first session, the importance of the mother's role in sex education of children was emphasized and the topics include the concept of sex education, teaching the right techniques of communication with children, familiarization with physiology and sexual behaviors of children. In the second session, the main topics were common questions of children, evaluation of various child sex education methods used by parents, enlightenment and confronting irrational and superstitious thoughts, and evaluation of mothers' viewpoints. In the third session, the researchers focused on the education of skills to cope with and respond to curiosities and sexual behaviors and questions of children. In order to complete the discussed topics, an educational booklet was given to the members of the intervention group, and during the training sessions, reminders about completing the educational content were done with the help of cyberspace, SMS, and telephone calls for mothers. In addition, the researchers attempted to answer any questions raised by

\footnotetext{
1. Student Research Committee, School of Medicine, Alborz University of Medical Sciences, Karaj, Iran.

${ }^{2}$. Assistant Professor, Social Determinants of Health Research Center, Alborz University of Medical Sciences, Karaj, Iran (Corresponding author) Tel: $(+26) 34483105 \quad$ Email: Dr.akbarikamrani@abzums.ac.ir

${ }^{3}$. Associate Professor, Reproductive Health Promotion Research Center, Ahvaz Jundishapur University of Medical Sciences, Ahvaz, Iran

${ }^{4}$. Assistant Professor, Non-Communicable Diseases Research Center, Alborz University of Medical Sciences, Karaj, Iran
} 
mothers. In order to observe ethics in research, an educational booklet was provided to the participants in the control group at the end of the study, and a workshop was held by the researcher to answer any questions in this area. The participants filled the questionnaires before and one month after the research. Moreover, data analysis was performed in SPSS version 16 using descriptive statistics (mean, standard deviation, and frequency) and analytical tests such as paired and t-tests, Chi-square, and its non-parametric equivalents (Mann-Whitney U and Wilcoxon test).

Results: In this study, there was no significant difference between the intervention $(32.28 \pm 3.71)$ and control $(35.16 \pm 4.55)$ groups regarding maternal age $(\mathrm{P}=0.690)$. The difference between the groups was assessed using Chi-square. According to the results, there was no significant difference between the groups regarding the age range of child, child's gender, number of children, child's birth rank, marital status, marital level of education, parental level of education, and parental occupational status. The results of the Mann-Whitney U test indicated a significant difference between the intervention and control groups in terms of the mean score of maternal knowledge of the sex education of children after the educational program $(\mathrm{P}=0.007)$. The results were also indicative of a significant difference between the mean knowledge score of mothers in the intervention group before and after the intervention $(\mathrm{P}=0.002)$. In addition, the results of the independent $\mathrm{t}$-test denoted a significant difference between the intervention and control groups in terms of the mean attitude score of mothers after the training $(\mathrm{P}=0.007)$. In addition, the mean attitude score of mothers significantly increased after education in the intervention group. In this regard, the mean attitude score of mothers increased by 6.28 after training $(\mathrm{P}=0.003)$. Moreover, the results of the paired t-test showed a significant difference in the mean score of the maternal participation approach in the two groups before and after the intervention as the score increased after the educational program $(\mathrm{P}=0.0001 ; \mathrm{t}(24)=8.440)$.

Conclusion: According to the results, the mothers reported more participation in the sex education of their children after the educational intervention. In order to increase the participation of mothers in sex education of their three to the seven-year-old child, it is recommended to use group education based on knowledge in a stressfree environment. Therefore, it is recommended that seminars, workshops, and counseling sessions be provided for parents, as well as caregivers in child care centers. The need to attend these classes as ongoing retraining is inevitable to promote the participation of women who will become mothers in the near future concerned about the sexual development of their children. Attending these courses helps women provide a healthy sexual life in childhood, sexual health in a future life for their child, and maintain the foundation of the family. Since both parents and primary caregivers of the child play an important role in their sexual education, the lack of study of fathers was a limitation of this study. Therefore, it is suggested that fathers and caregivers be trained in similar studies.

Keywords: Knowledge, Attitude, Participation, Mothers, Preschool Child, Sex Education

\section{Conflict of Interest: No}

How to Cite: Fatehi Pouladi H, Akbari Kamrani M, JavadNoori M, Farid M. Effectiveness of a Group Educational Program on the Knowledge, Attitude, and Participation Approach of Mothers in the Sex Education of Preschool Children. Iran Journal of Nursing. 2019; 32(119):13-25.

Received: 6 May 2019

Accepted: 5 Aug 2019 


\title{
اثربخشى يك برنامه آموزشى تروهى بر آكاهى، نكرش و مشاركت مادران در آموزش جنسى

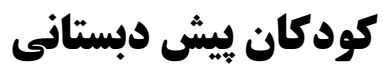

\author{
حديث فاتحى يولادى ', مهرناز اكبرى كامر انى '، مزَّان جوادنورى بّ، مليحه فريدع
}

جكيله

زمينه و هدف: خانواده، به ويزه مادران نقش مؤثرى در تربيت جنسى كودكان دارند، لذا توجيه ضرورت تربيت جنسى كودى توسط والدين امرى لازم

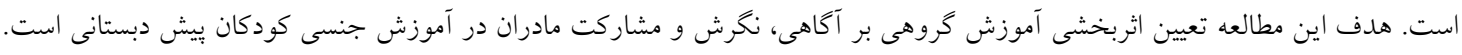

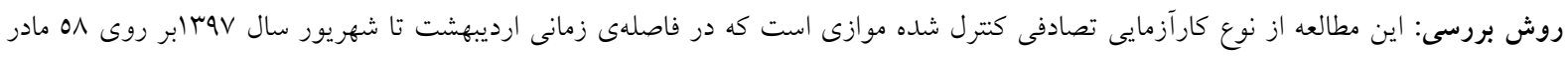

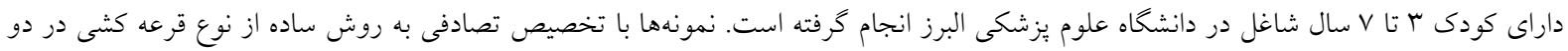

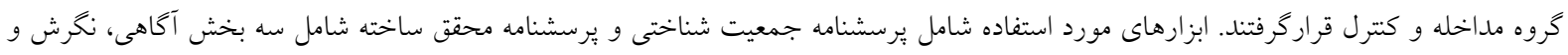

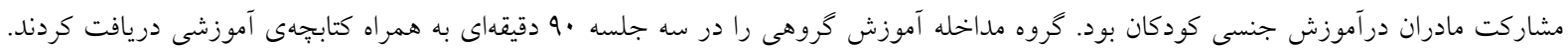

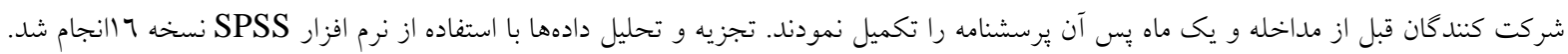

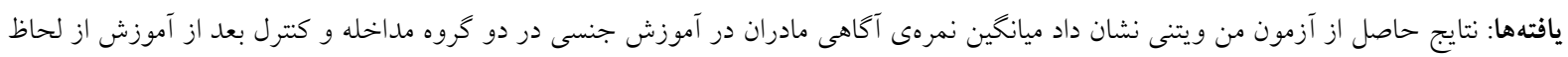

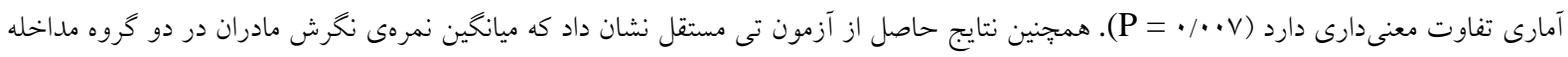

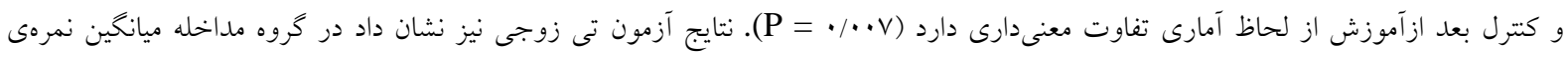

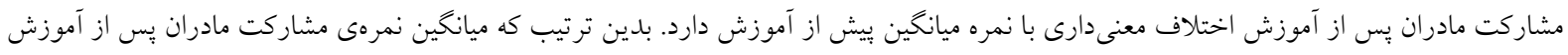
افزايش يافته است ( P

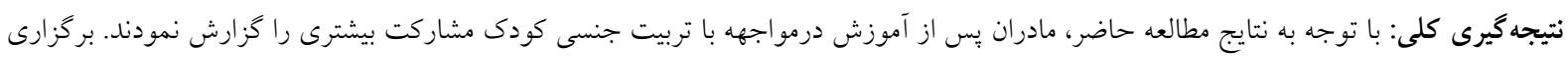
جلسات و كاركاههاى آموزشى و مشاورهاى ويزه والدين، مربيان و مراقبين كودكان در مراكز نخهدارى كودى، يُشنهاد مى گردد.

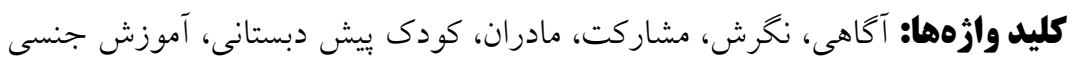
تعارض منافع: ندارد تاريخ دريافت: $7 \Lambda / T / 17$

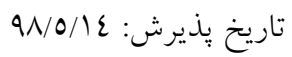

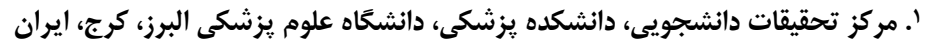

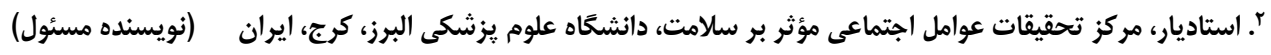
Email: Dr.akbarikamrani@abzums.ac.ir

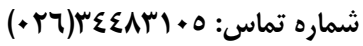

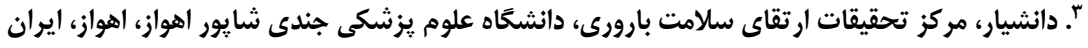

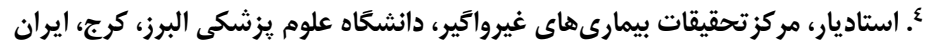


ازآنجايى كه والدين در مورد آموزش مسائل جنسى

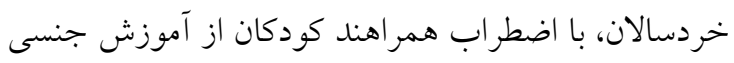

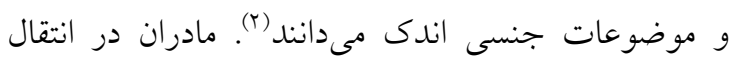

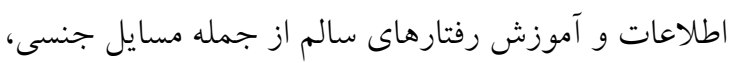

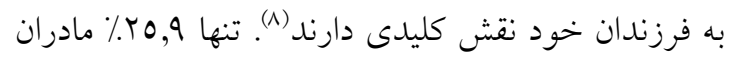

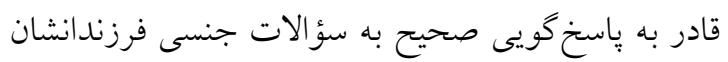

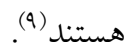

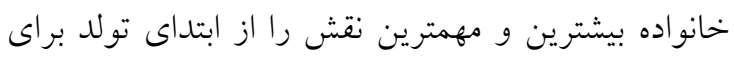

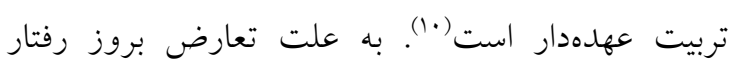

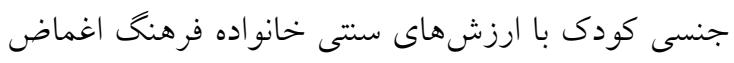
و سكوت در مديريت رفتارجنسى كودى به هنجار تبديل شده است (11). باسخ به كنجكاوىهاى جنسى كودى نه تنها باعث فعاليت

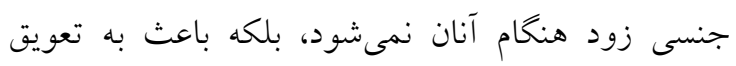

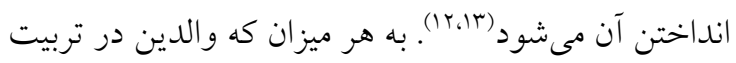

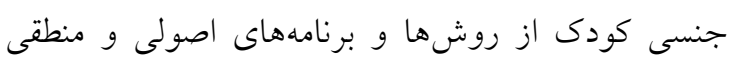

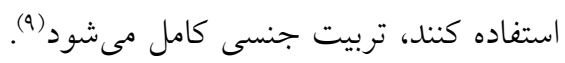

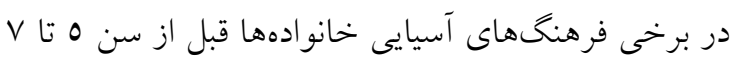

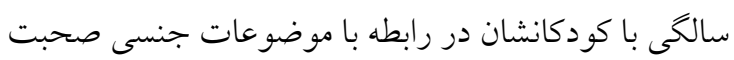

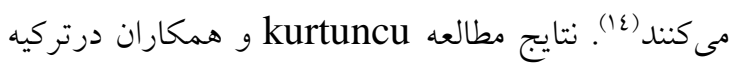

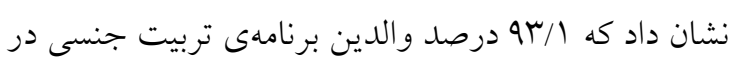

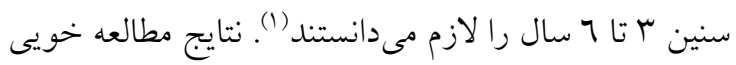

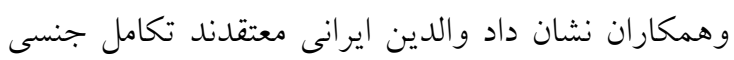

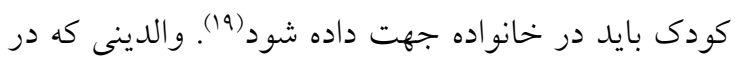

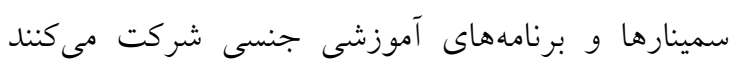

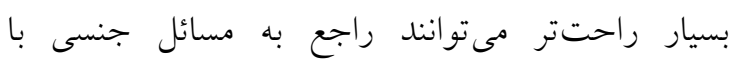

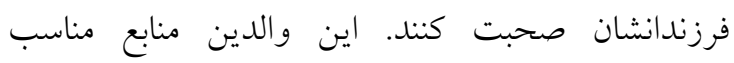
خواندنى را دربارهى مسائل جنسى براى فرزندان خود

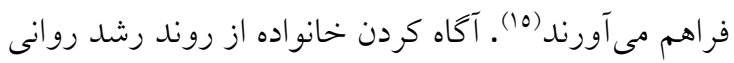

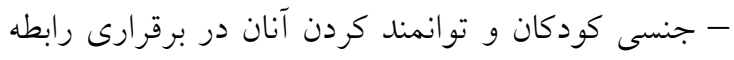
مطلوب به برخورد اصولى خانواده با مسائل و مشكلات جنسى كودى منجرخواهد شد. خانواده به عنوان اولين به بوني كانون منبع كسب اطلاعات كودكان اهميت فوق العادهاى در شكل گيرى و تكامل رفتارى كودكان دارد. خانواده

\section{مقدمه}

سال هاى ييش از دبستان براى كودكان، دورهاى بسيار مهم

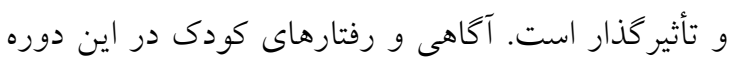
شكل مى گيرد (1) والدين در مورد مسائل جنسى اغلب با سئو الاتى از طرف

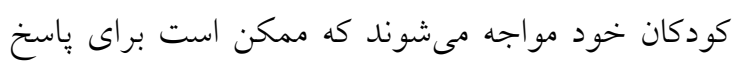

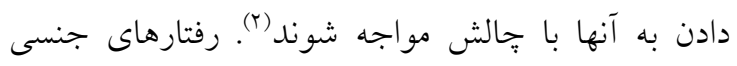

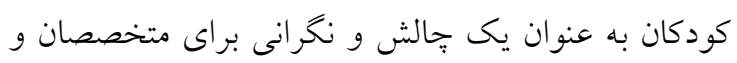
همجنين والدين در سراسر جهان مطرح است (r).

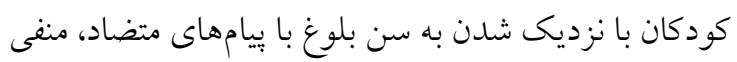

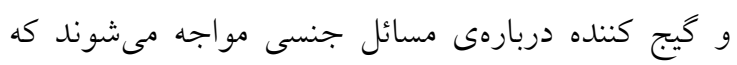

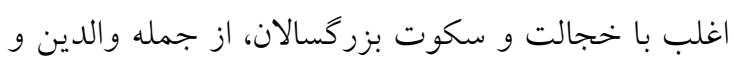

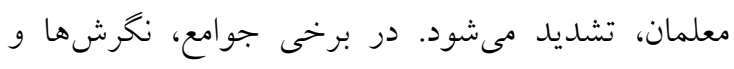

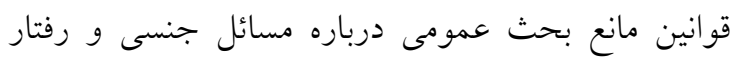
جنسى مىشوند و هنجارهاى اجتماعى ممكن است شر ايط مضر را تقويت كنند (ع).

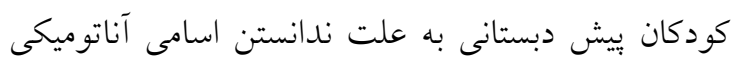

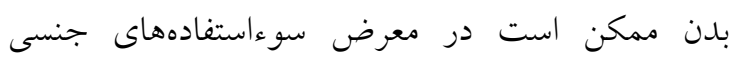

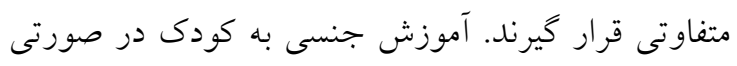

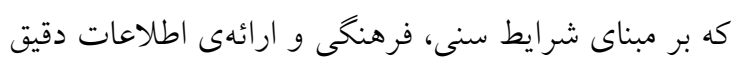

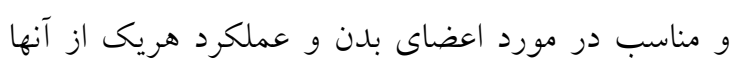

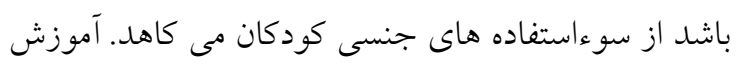

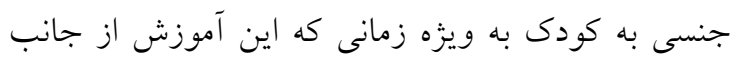

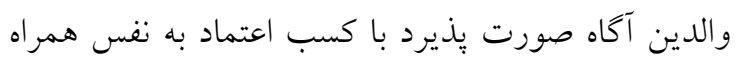

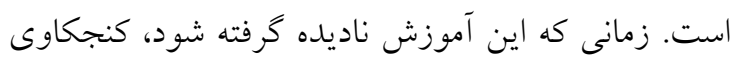

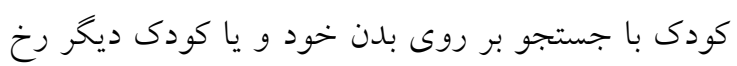
خواهد داد (0). تعامل بين والدين مىتواند يكى عامل حفاظتى براى طيف وسيعى از رفتارهاى جنسى فرزندان در آينده باشد (1).

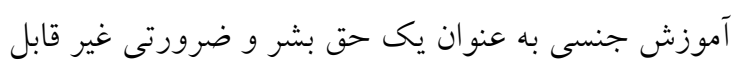

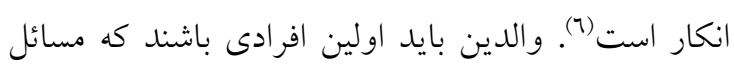

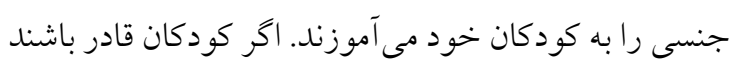
در مورد يرسش هاى جنسى خود با والدين صحبت كنّلد،

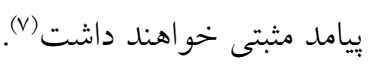


تكاملى گردند (r.). آموزش بهداشت گروهى رويكردى

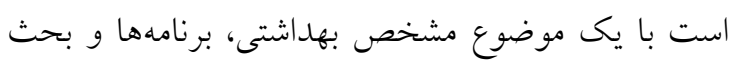

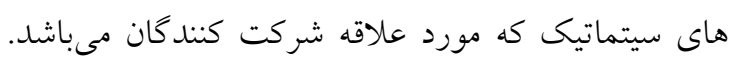

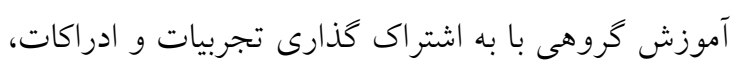

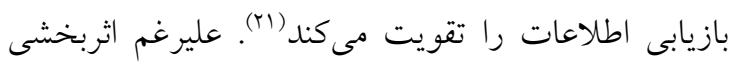

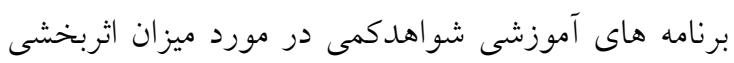

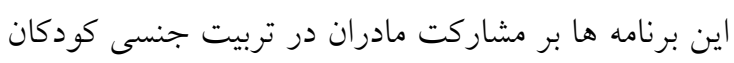

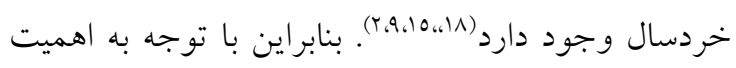

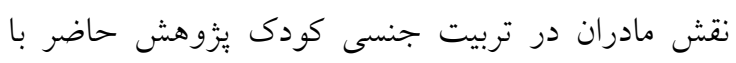
هدف بررسى اثربخشى آموزش گروهى بر آكاهى، نحرش

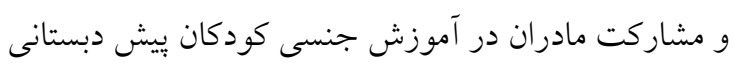

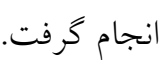

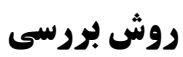
اين مطالعه از نوع كارآزمائى تصادفى كنترل شده موازى بـ است (IRCT20160423027557N7) كه در فاصله

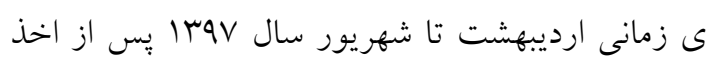
مجوز از كميته اخلاق دانشكاه علوم يزشكى البر البرز

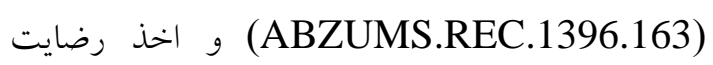
آكاهانه بر روى ON مادر داراى كودى سه تا هفت سال

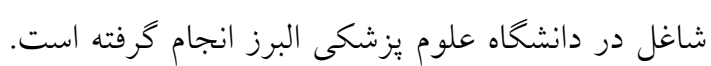

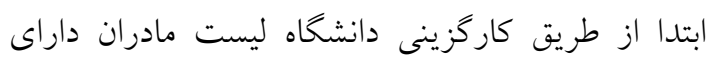

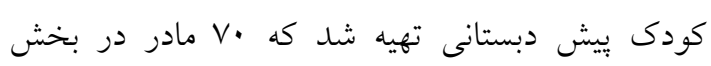

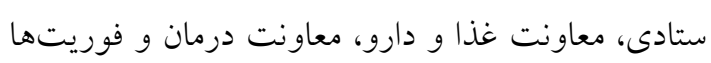
شناسايى شدند. در اين مطالعه جهت به حداقل رساندن

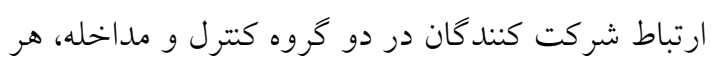

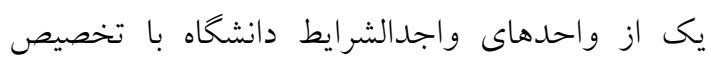

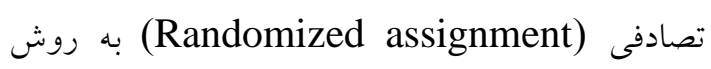

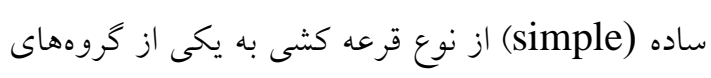

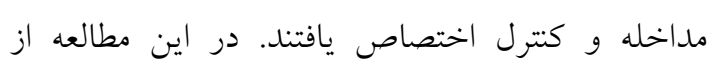

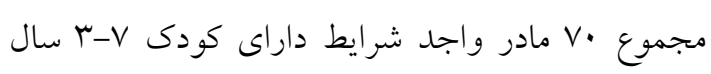

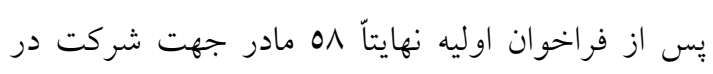

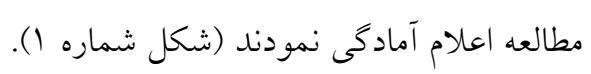

نخستين گروهى است كه بايد مسئوليت آموزش فرزندان

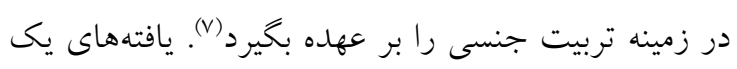

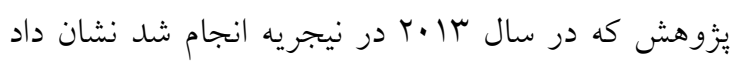

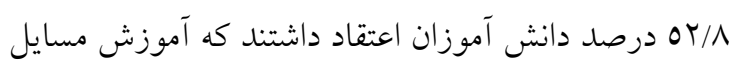
جنسى بايد در خانه توسط والدين داده شود ولى والدين منبع اطلاعاتى ضعيفى براى دانش آموزان بودند (17). غالباّ كفتخوى بين و الدين و فرزندان در اين زمينه غير مستقيم و

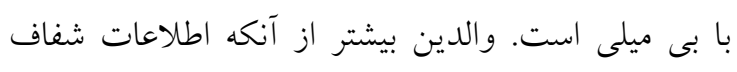

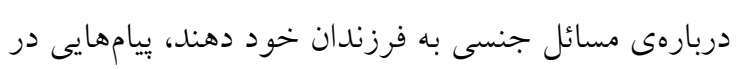
مورد اخلاق جنسى مى دهند. اين بيامها معمولاّ منفى و

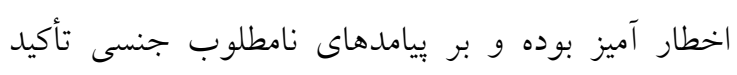

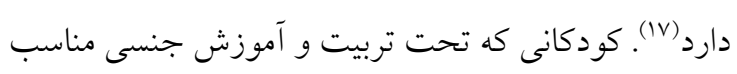

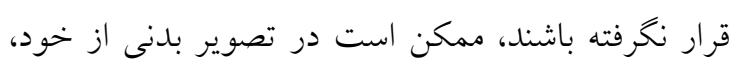

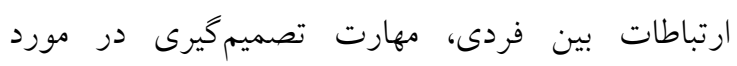

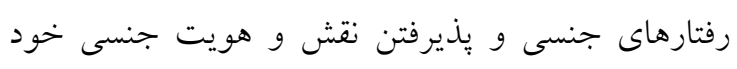

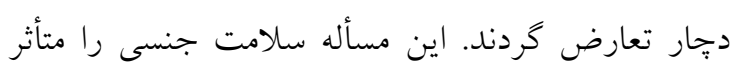

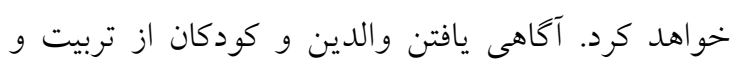
آموزش جنسى به موقع و متناسب با سن كودى درد در ورد يُشيرى از انواع سوء استفادههاى جنسى از كودكان مؤثر

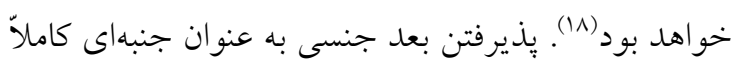

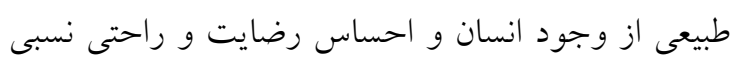

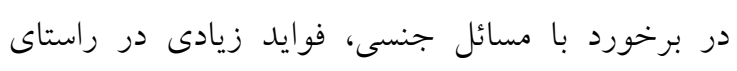

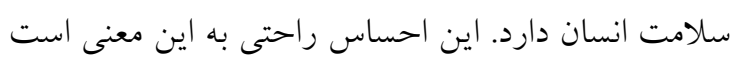

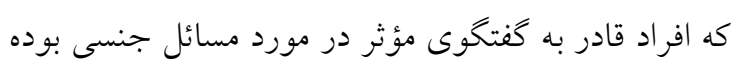
و نسبت به طبيعت و ماهيت جنسى خويش احساس امنيت

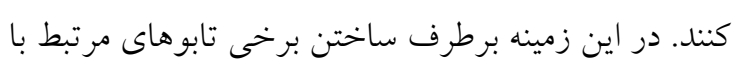

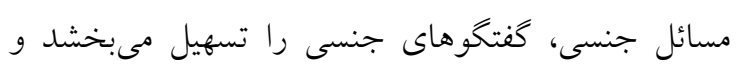
كمك شايانى به ارتقاى سلامت جنسى كودكان مى جى نمايد (19) از بين شيوههاى آموزشى مؤثر، آموزش گروهى، يكى فرايند

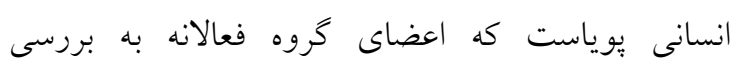

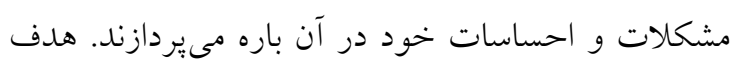

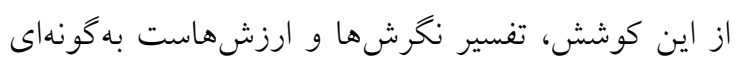

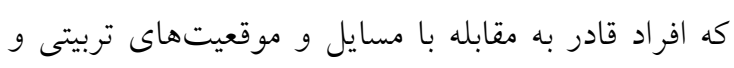




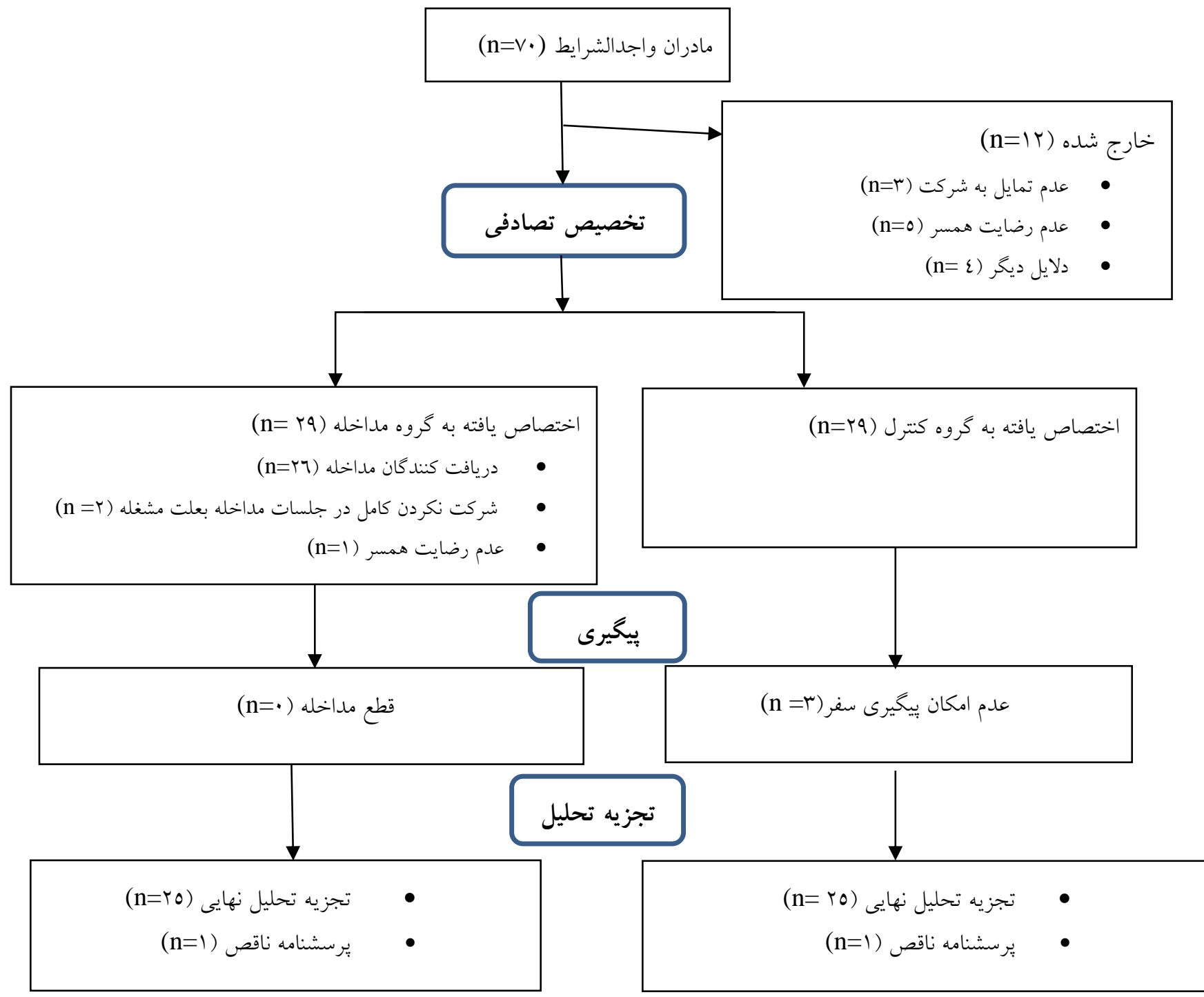

شكل شماره ا: نمودار CONSORT

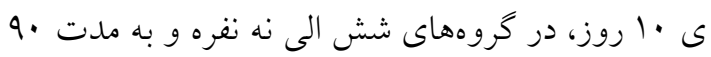
دقيقه درسالن جلسات هريك از واحدها انجام گرفت. در كروه مداخله، آموزش گروهى مادران از طريق بارش افكار، بيان تجربيات نفر به نفر، نمايش انيميشن و جمع بندى مشكلات مشابه مادران در حوزهى آموزش جنسى كودكان توسط ماماى دوره ديله تحت نظر يك تيم از متخصصان سلامت بارورى انجام شد. در نهايت ياد گيرى فعال و به صورت گروهى انجام گرفت. جهت تكميل مباحث مطرح شده كتابجهى آموزشى به افراد كروه مداخله داده شد. - ملت محتوى جلسات عبارت بود از جلسه اول: مقدمه و بيان اهميت نقش مادر در تربيت و آموزش جنسى، مفهوم
از فرمول آزمون دو ميانخين مربوط به يك صفت كمى در دو جامعه مستقل جهت تعيين حجم نمونه اين مطالعه استفاده گرديد. بر اساس مطالعه Lee\& Kweon حجم نمونه در هر كروه ro نفر محاسبه گرديد (rI). معيارهاى ورورد به مطالعه شامل اشتغال در دانشخاه علوم يزشكى البرز به عنوان كارمند، مادر يا مراقب اصلى كودى بودن، داشتن سواد خواندن و نوشتن، تسلط به زبان فارسى و شركت نكردن در دورههاى تربيت جنسى كودى در شش ماه كذشته بود. معيارهاى خروج از مطالعه شامل تمايل نداشتن به ادامه شركت در مطالعه و عدم شركت در تمامى جلسات آموزش تعيين شده بود. جلسات آموزشى درگروه مداخله طى سه جلسه با فاصله 
مواجهه مادران را با سئوالات و رفتارهاى كودى در 11 موقعيت (تفاوتهاى زنان و مردان، توليد مثل، حريم

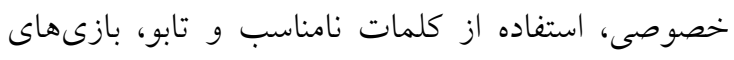

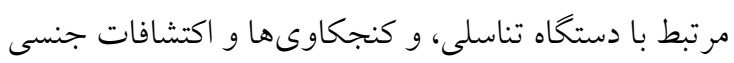

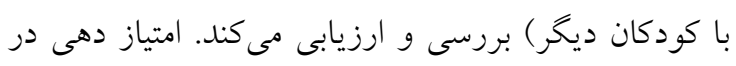

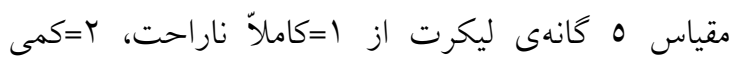

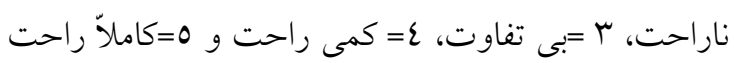

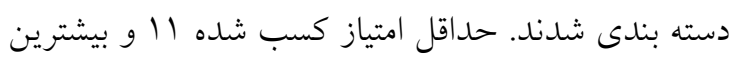

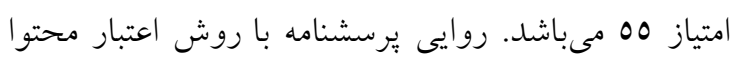

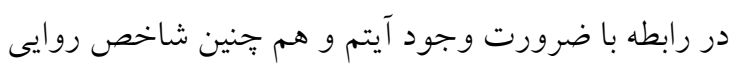
محتوا جهت بررسى تناسب، وضوح و مربوط بودن آيتمها

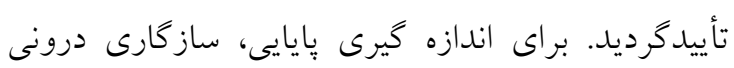

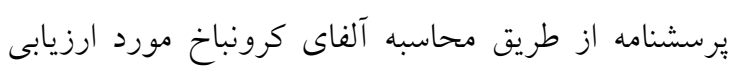

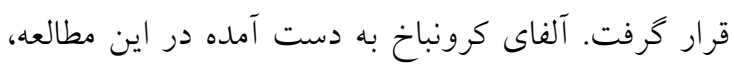

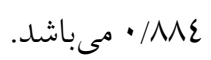
پِ از جمع آورى اطلاعات، دادهاى اخذ شده با استفاده

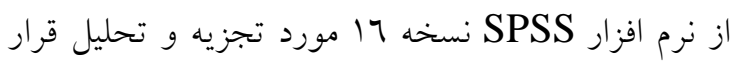
كرفت. از آمارههاى توصيفى شامل ميانخين، انحر اف معيار

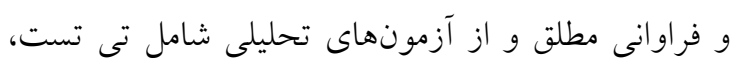

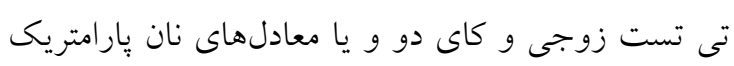

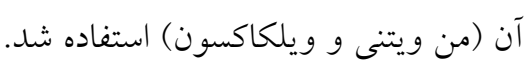

\section{يافتهها}

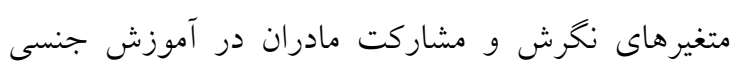

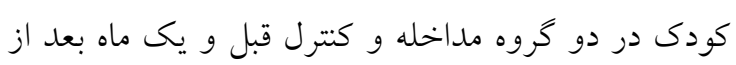

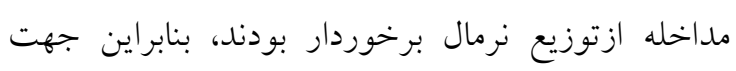

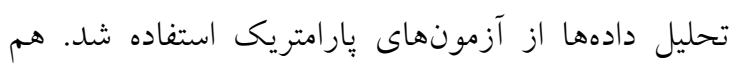

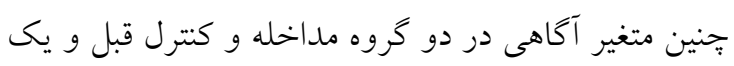

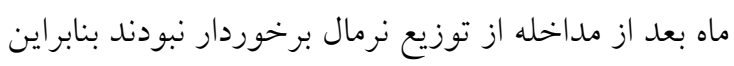

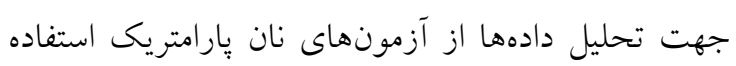

متوسط سن شركت كنندكان در كروه مداخله (

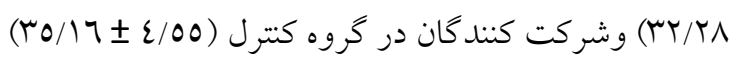
بوده است. نتايج حاصل از آزمون من ويت نى نش نشان مي كى
تربيت جنسى, آموزش تكنيكهاى صحيح ارتباط با كودى، آشنايى با فيز يولوزى و رفتارهاى جنسى كودئ تحني

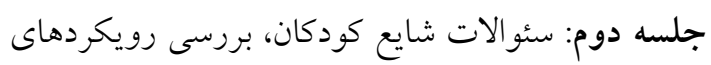

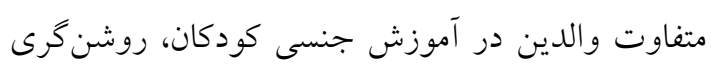

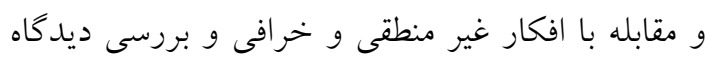

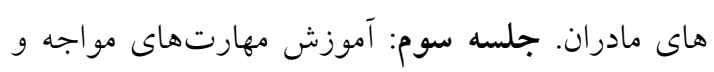

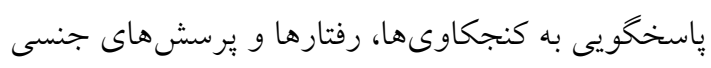

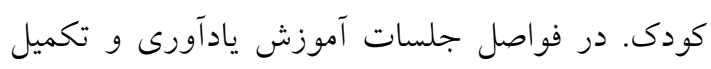
محتواى آموزشى به كمك فضاى مجازى، يبيامك و تماس

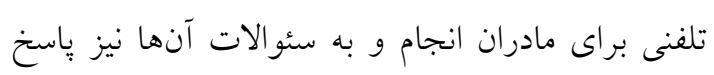

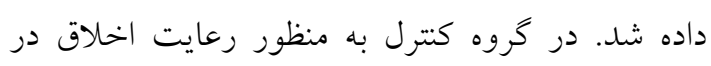

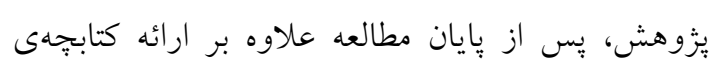

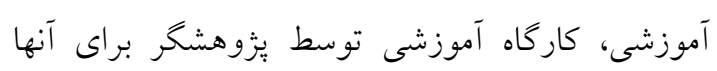

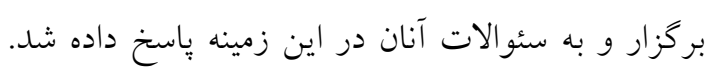

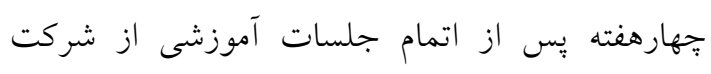

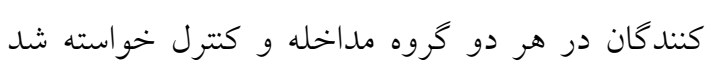
مجدداً يرسشنامه ها را تكميل نمايند.

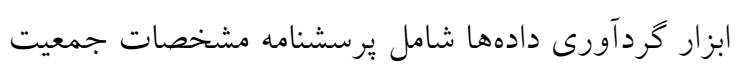
شناختى و يرسشنامه محقق ساخته مشاركت مادران درد درد

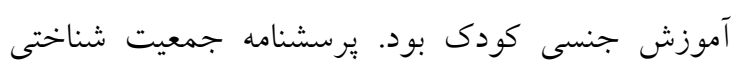

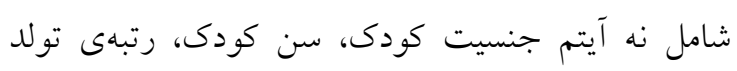
كودى، تعداد فرزندان، سن، وضعيت تأهل و تحصيلات

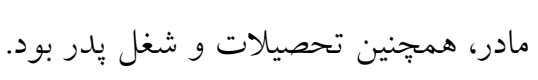

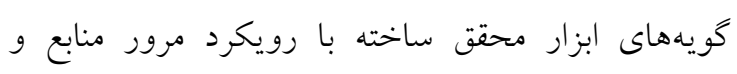

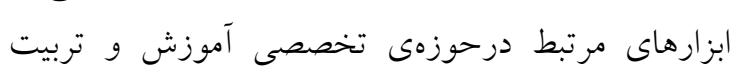

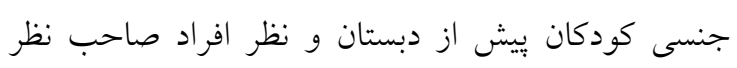

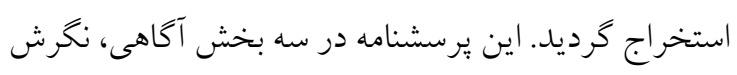
و مشاركت مادر نسبت به آموزش جنسى كودى تنظيم

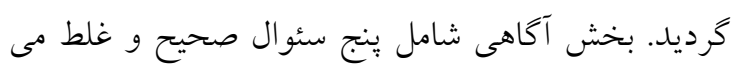

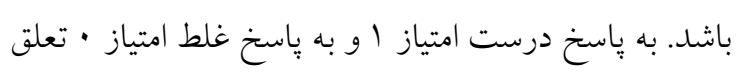

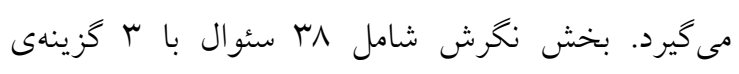

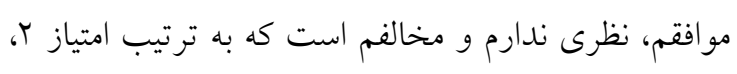

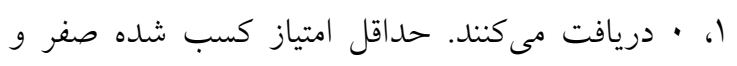

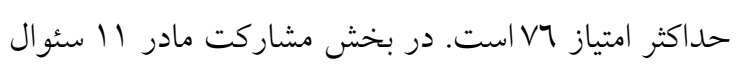


دهد كه سن مادر در گروه مداخله در مقايسه با گروه كتترل كودى، جنس فرزند خانواده، تعداد فرزند، رتبه فرزند،

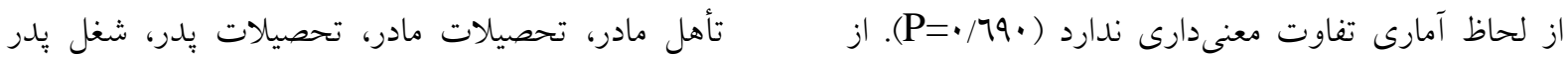

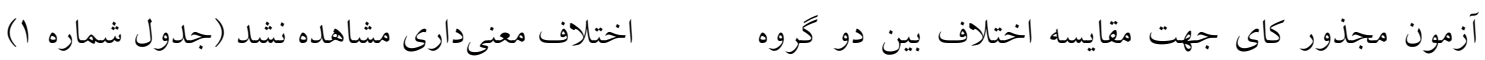

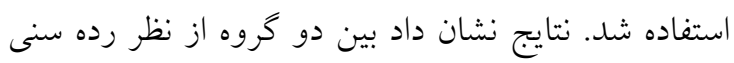

جدول شماره (: مقايسه متغيرهاى جمعيت شناختى در دو كَروه مداخله و كنترل

\begin{tabular}{|c|c|c|c|c|c|c|}
\hline P value* & $\mathrm{X}^{2}$ & df & Sروه كترل (\%) & Sروه مداخله (\%) & \multicolumn{2}{|c|}{ متغيرها } \\
\hline \multirow[t]{4}{*}{.1001} & & & $\operatorname{Ir}(\varepsilon \wedge)$ & Ir (Or) & ع-"r سال & \\
\hline & $r / l \cdot V$ & r & $\varepsilon(17)$ & $r(\Lambda)$ & 0-ع سال & سن كودى \\
\hline & & & $T(Y \varepsilon)$ & $\varepsilon(17)$ & 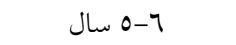 & \\
\hline & & & $r(I r)$ & $T(r \varepsilon)$ & 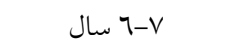 & \\
\hline \multirow[t]{2}{*}{1} & $\cdot / \cdot$ & 1 & Ir (Or) & Ir (Or) & دختر & جنسيت كودى \\
\hline & & & $K(\Sigma \wedge)$ & $K(\varepsilon \wedge)$ & מֶ & \\
\hline \multirow[t]{4}{*}{$\cdot / V 71$} & . /2TV & r & $11(\varepsilon \varepsilon)$ & $\operatorname{lr}(O r)$ & 1 & \\
\hline & & & Ir (Or) & $11(\varepsilon \varepsilon)$ & r & \\
\hline & & & - & I( $\varepsilon)$ & r & تعداد فرزندان \\
\hline & & & I(घ) & . & $\varepsilon$ & \\
\hline \multirow[t]{4}{*}{$\cdot / 1 \Lambda$. } & $1 / N T 7$ & r & $\operatorname{lr}(O r)$ & $11(\varepsilon \varepsilon)$ & 1 & رتبه فرزندان \\
\hline & & & $11(\varepsilon \varepsilon)$ & $T(Y \varepsilon)$ & r & \\
\hline & & & . & 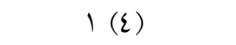 & r & \\
\hline & & & 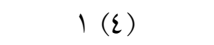 & . & $\varepsilon$ & \\
\hline \multirow[t]{2}{*}{1} & 1 & 1 & ro $(1 .)$. & $T \varepsilon(97)$ & با همسر & وضعيت تأهل مادر \\
\hline & & & - & 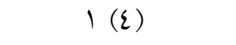 & جدا از همسر & \\
\hline \multirow[t]{2}{*}{$\cdot / \pi \varepsilon q$} & $\cdot r \varepsilon q$ & r & $\varepsilon(17)$ & 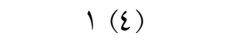 & كمتراز دييلم و دييلم & ميزان تحصيلات مادر \\
\hline & & & $Y \backslash(\Lambda \varepsilon)$ & $T \varepsilon(97)$ & كارشناسى و بالاتر & \\
\hline \multirow[t]{5}{*}{. $/ r r}$. & $\cdot / r T$. & $\varepsilon$ & $r(\Lambda)$ & - & كمتر از دييلم & \\
\hline & & & $V(r \Lambda)$ & $0(T \cdot)$ & دييلم & \\
\hline & & & $1 \cdot(\varepsilon \cdot)$ & $9(47)$ & كارشناسى & ميزان تحصيلات يدر \\
\hline & & & $O(T)$ & $11(\varepsilon \varepsilon)$ & كارشناسى ارشد & \\
\hline & & & I(घ) & . & دكترا & \\
\hline \multirow[t]{4}{*}{. $/ \pi r}$. & D RT. & $\varepsilon$ & 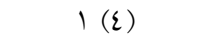 & - & بيكار & \\
\hline & & & $17(7 \varepsilon)$ & $19(7 \varepsilon)$ & 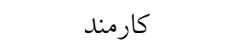 & شغل يدر \\
\hline & & & $T(Y \varepsilon)$ & $O(r \cdot)$ & آزاد & \\
\hline & & & $r(\Lambda)$ & 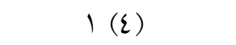 & ساير & \\
\hline
\end{tabular}

معنى دارى ندارد ( P=•/1/9). همجنين نتايج نشان مى دهد كه ميانكين نمرهى آكاهى مادران در آموزش جنسى در دو
نتايج حاصل از آزمون من ويت نى نشان مىدهد كه ميانگين نمرهى آكاهى مادران در آموزش جنسى در دو كروه مداخله و كنترل قبل از آموزش از لحاظ آمارى تفاوت 
است (P=/07ع). هم جنين نتايج نشان مىدهد كه

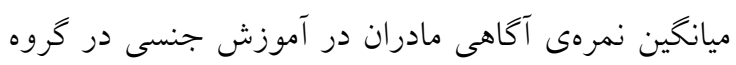

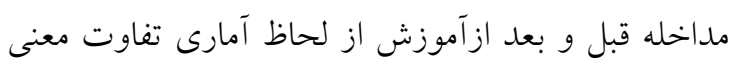

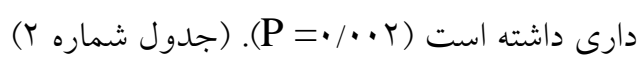

كروه مداخله و كتترل بعد از آموزش از لحاظ آمارى تفاوت

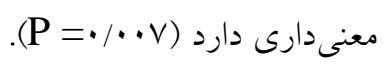

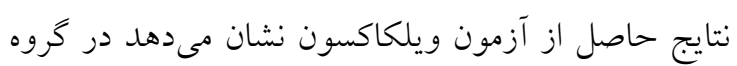

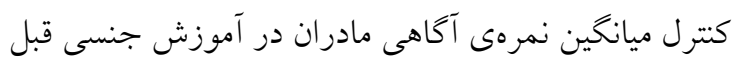

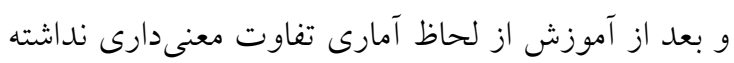

\begin{tabular}{|c|c|c|c|c|c|}
\hline$* \mathbf{P}$ value & $\mathbf{Z}$ & مداخله & كتترل & & متغير \\
\hline \multirow[t]{3}{*}{.$/ 199$} & \multirow[b]{2}{*}{$-1 / \gamma \Lambda$} & $r / \varepsilon$. & $r / \uparrow$ & ميانخين & \multirow[t]{2}{*}{ قبل از آموزش } \\
\hline & &.$/ 91$ & $1 / \cdot 7$ & انحراف معيار & \\
\hline & & $\varepsilon / T r$ & $r / \wedge$. & ميانكين & بعد از آموزش \\
\hline \multirow[t]{3}{*}{ 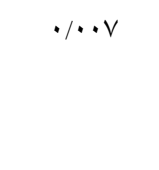 } & $-Y / T V$ & $\cdot / \wedge \cdot$ & $\cdot / 7 \varepsilon$ & انحراف معيار & \\
\hline & & $-r / .0$ & $-\cdot$ No & \multicolumn{2}{|c|}{$\mathrm{Z}$} \\
\hline & & $\cdot / \cdot r r$ & $\cdot 107 \varepsilon$ & & \\
\hline
\end{tabular}

* ويلكاكسون

نتايج حاصل از آزمون تى زوجى نشان مىدهد در گروه

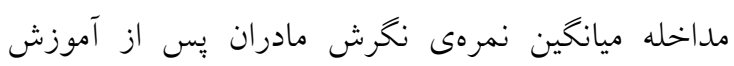

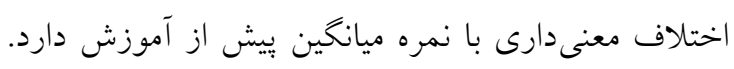

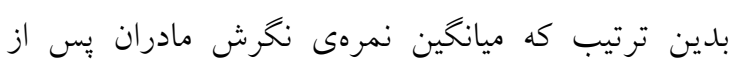

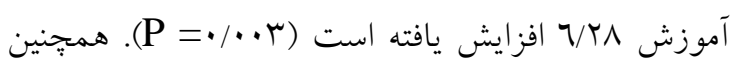

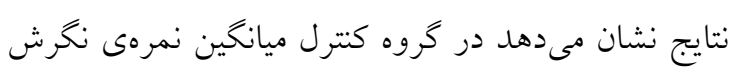

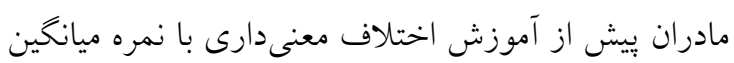

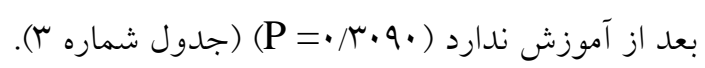

جدول شمارهب: توزيع ميانكَين و انحراف معيار نمرهى نحَرش مادران در آموزش جنسى قبل و بعد از آموزش در دو تَروه مداخله وكتترل

\begin{tabular}{|c|c|c|c|}
\hline & مداخله & كنترل & متغير \\
\hline$t=1 / 09$ & $\{\wedge / \Gamma\}$ & $\sum V / 9 Y$ & قبل از آموزش \\
\hline $\mathrm{df}=\varepsilon \wedge$ & $1 / 90$ & N/AY & انحراف معيار \\
\hline
\end{tabular}

$* \mathrm{P}$ value $=\cdot / \wedge \uparrow$

\begin{tabular}{|c|c|c|c|c|}
\hline $\mathrm{t}=-\Lambda / v$ & $0 \varepsilon / 7 \varepsilon$ & $\sum 9 / \Gamma \wedge$ & ميانگين & بعد از آموزش \\
\hline$d f=\varepsilon \wedge$ & $0 / \pi r$ & V/Ar & انحراف معيار & \\
\hline$* \mathrm{P}$ value $=\cdot / \cdot v$ & $\begin{array}{l}\mathrm{t}=\cdot N \mathrm{l} \\
\mathrm{df}=r_{0}\end{array}$ & $\begin{array}{c}\mathrm{t}=-1 / 19 \\
\mathrm{df}=\mathrm{r} \varepsilon\end{array}$ & & \\
\hline
\end{tabular}

$* \mathrm{P}$ value $=\cdot / \cdots+\quad * \mathrm{P}$ value $=\cdot / r \varepsilon 0$
نتايج حاصل از آزمون تى مستقل نشان مى دهد كه ميانكين

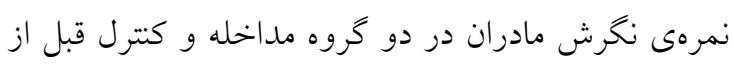

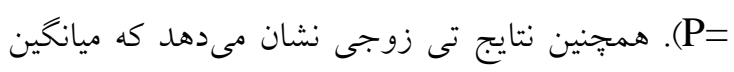

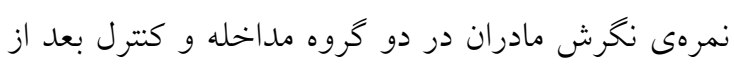

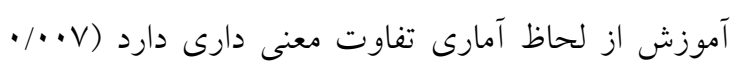

. $\mathrm{P}=$

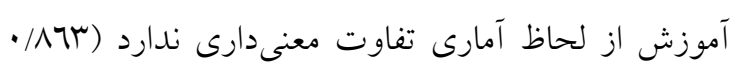


اختلاف معنى دارى با نمره ميانخين بيش از آموزش دارد.

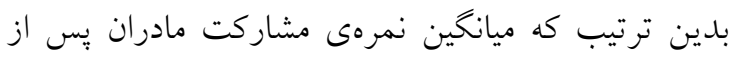

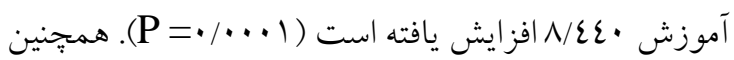

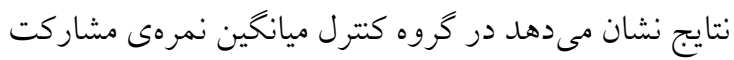
مادران بيش از آموزش اختلاف معنى دارى با نمره ميانخين

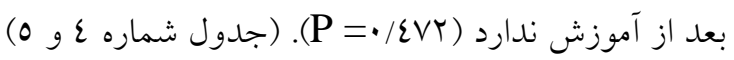

نتايج حاصل از آزمون تى مستقل نشان مى دهد كه ميانخين

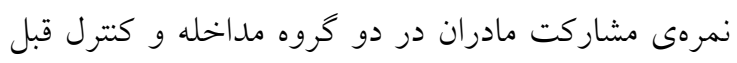

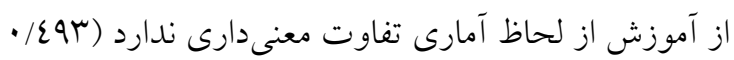
P =

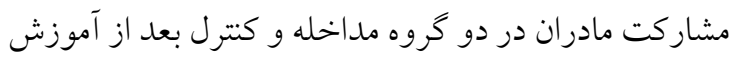

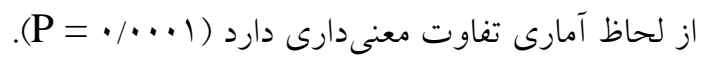

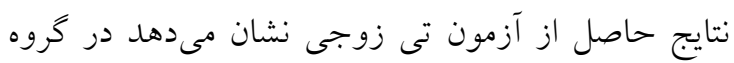

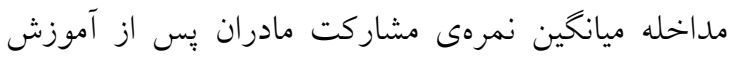

جدول شمارهع: توزيع تفاوت ميانكين نمرهى مشاركت مادران قبل و بعد از آموزش در تروه مداخله و كنترل

\begin{tabular}{|c|c|c|c|}
\hline *P value & مداخله & كنترل & متغير \\
\hline$t=\cdot / 79$ & $r\urcorner / V 7$ & ro/97 & قبل از آموزش \\
\hline$d f=\varepsilon \wedge$ & $\varepsilon / 7 \Gamma$ & $r / 27$ & انحر اف معيار \\
\hline
\end{tabular}

$* \mathrm{P}$ value $=\cdot / \varepsilon q r$

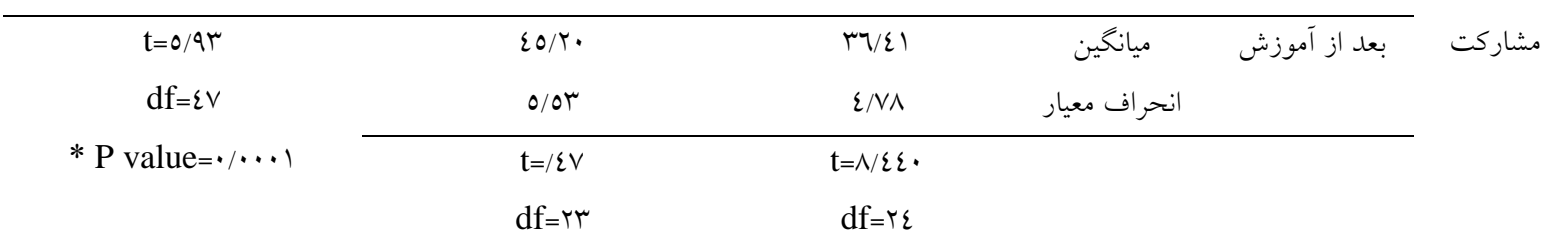

$* \mathrm{P}$ value $=\cdot \cdots \cdot \quad * \mathrm{P}$ value $=\cdot / \mathrm{N}^{\mathrm{I}}$

جدول شماره ه: توزيع تفاوت نمره مشاركت مادران قبل و بعد از مداخله

تفاوت نمره مشاركت مادران قبل و بعد از مداخله

\begin{tabular}{|c|c|c|c|c|}
\hline \multicolumn{2}{|c|}{ 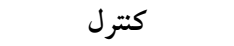 } & \multicolumn{2}{|c|}{ 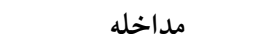 } & \multirow[t]{2}{*}{ آيتمهاى مشاركت } \\
\hline $\mathrm{Z}^{*}$ & $\mathrm{P}$ & $\mathrm{Z}^{*}$ & $\mathrm{P}$ & \\
\hline$-1 / T \cdot V$ & $\cdot /$ TYV & $-1 / T \wedge V$ &.$/ 191$ & صحبت كردن مادر در مورد تفاوتهاى بين مردان و زنان با كودى \\
\hline$-1 / 00 \varepsilon$ & $\cdot / T r$ & $-r / \cdot 11$ & 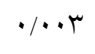 & صحبت كردن مادر در مورد توليد مثل و تولد با كودى \\
\hline$-\cdot / \varepsilon r$ & $\cdot / 777$ & $-Y / \wedge 07$ & $\cdot \cdots \varepsilon$ & صحبت كردن مادر در مورد حريم خصوصى با كودى \\
\hline$\cdot \cdot \cdot 1$ & $1 / \cdots$ & $-r / 910$ & $\cdot \cdots \cdot$ & مو اجه با بازى كودى با آلت تناسلى اش \\
\hline$-1 / V \vee 7$ & $\cdot / \cdot \vee 7$ & $-\cdot / 0 Y \Lambda$ & $.109 \mathrm{~V}$ & استفاده كودى از كلمات عاميانهى جنسى \\
\hline$\cdot / \cdot 1$ & $1 / \cdots$ & $-r / r \varepsilon r$ & $\cdot \cdots 1$ & سئوال كودى كه جֶر إِسران آلت تناسلى دارند و دخترها ندارند. \\
\hline$-1 /$ T9Y &.$/ 197$ & $\varepsilon-/ 11 V$ & $\cdot \cdots \cdot 1$ & سئوال كودى كه بجهها از كجا مى آيند. \\
\hline$-r / \cdot 99$ & $\cdot / \mu\urcorner \cdot$ & T/NT. & $\cdot / \cdots \cdot$ & سئوال كودى كه جِكونه نوزادان داخل بدن مادر مىشوند. \\
\hline$-\cdot / r$ & $\cdot / 914$ & $-\cdot /$ Vor &.$/ 207$ & زمانى كه كودى آلت تناسلى خود را در بازى كشف مى كند. \\
\hline $1 \cdot / r r$ & $\cdot / 9 \cdot r$ & $-r / \cdot \vee V O$ & $\cdot \cdots r$ & زمانى كه كودى خود و دوستش را عريان در حال دكتر بازى مىيابيد. \\
\hline$-\cdot / \varepsilon \varepsilon r$ & $\cdot / 701$ & $\cdot$ • NTr & $\cdot / \varepsilon \varepsilon 7$ & سئوال كودى كه مى يرسد كه جرا شما وقت خواب درب اتاق خوابتان را مىبنديد. \\
\hline
\end{tabular}


كار انه استفاده مى كنند. تعداد كمى از والدين، معتقد بودند بحث و نتيجهكيرى

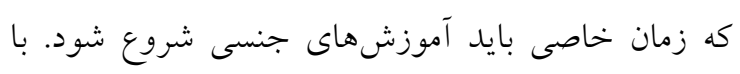

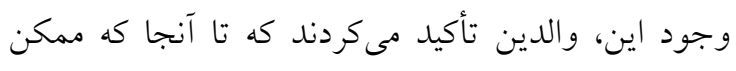

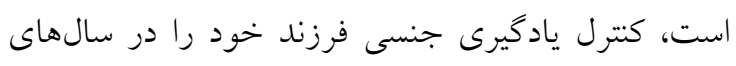

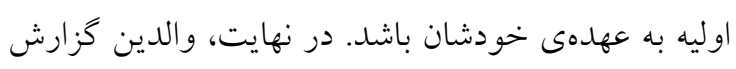

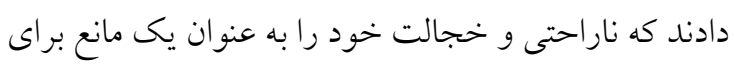

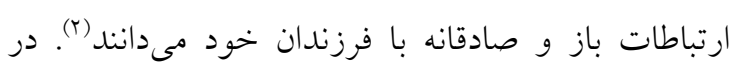
همين راستا، Wilson \& Dalberth به مطالعهى ديدكاه

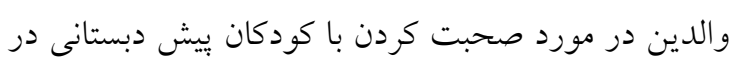

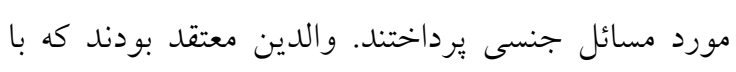

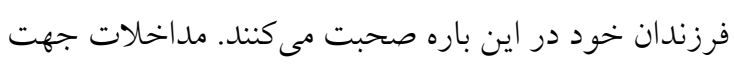
تشويق والدين به صحبت كردن با فرزندانشان درباره مسائل

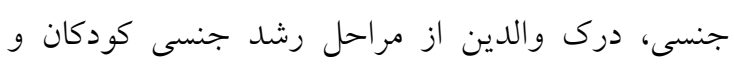

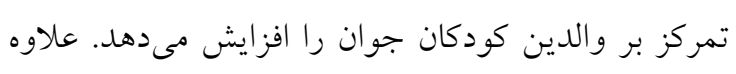

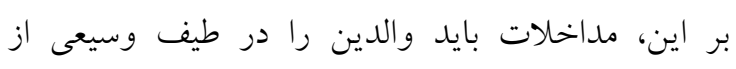
استراتزىهايى تكميل كننده مسائل جنسى، حمايت كند (IN).

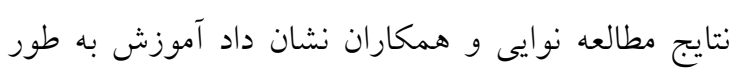

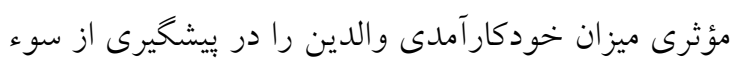
استفاده جنسى كودى داد (rr).

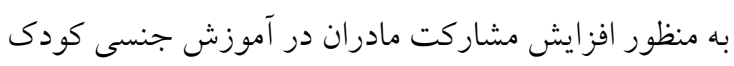

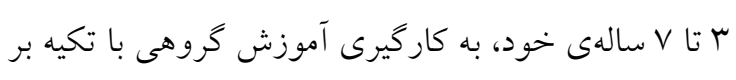
آكاهى و به دور از ترس و اضطراب توصيه مىشود.

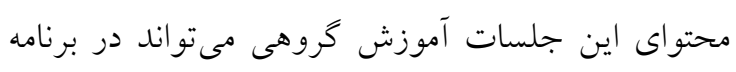

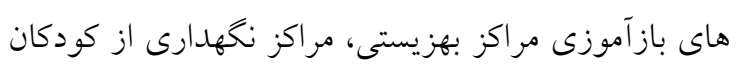

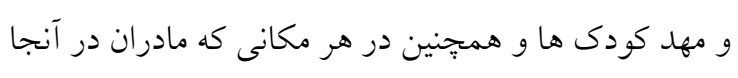

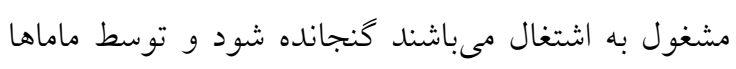
آموزش داده شود. ضرورت شركت در اين كلاسها به عنوان يكى بازآموزى مستمر جهت ارتقاء مشاركت زنانى كه درد

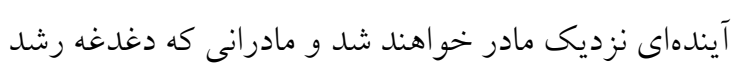

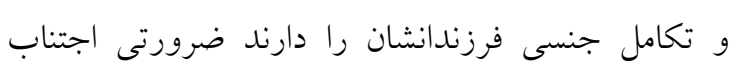

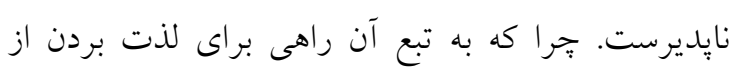

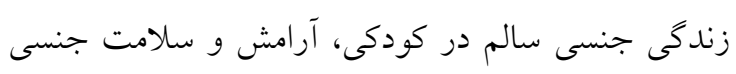
در زندكى آتى و همجنين حفظ بنيان خانو اده فراهم خو اهد وند شد. از آنجايى كه هر دو والد و مراقبين اصلى همنين كودى در بنيان 


$$
\begin{aligned}
& \text { تقدير و تشكر } \\
& \text { اين مقاله منتج از وِايان نامه دانشجوى كارشناسى ارشد }
\end{aligned}
$$

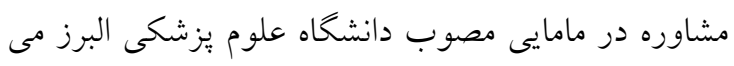

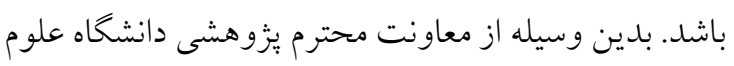

$$
\begin{aligned}
& \text { يزشكى البرز كه حمايت مالى اين طرح را بر عهلده داشتند }
\end{aligned}
$$

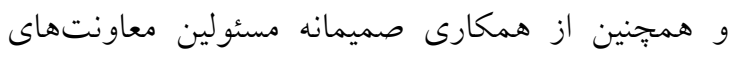

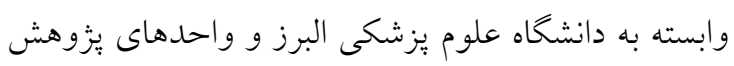

$$
\begin{aligned}
& \text { تشكر و قدردانى مىشود. }
\end{aligned}
$$

\section{References}

1. Kurtuncu M, Akhan LU, Tanir IM, Yildiz H. The sexual development and education of preschool children: knowledge and opinions from doctors and nurses. Sexuality and disability. 2015;33(2):207-21.

2. Stone N, Ingham R, Gibbins K. 'Where do babies come from?'Barriers to early sexuality communication between parents and young children. Sex Education. 2013;13(2):228-40.

3. Larsson I, Svedin CG. Sexual behaviour in Swedish preschool children, as observed by their parents. Acta Paediatrica. 2001;90(4):436-44.

4. Sutton MY, Lasswell SM, Lanier Y, Miller KS. Impact of parent-child communication interventions on sex behaviors and cognitive outcomes for black/African-American and Hispanic/Latino youth: A systematic review, 1988-2012. Journal of Adolescent Health. 2014;54(4):369-84.

5. Sandweg GS. Maternal Involvement in Preschoolers' Sexuality Education: A Comparison of Single and Married Mothers. 2003.

6. UNESCO. Emerging Evidence, Lessons and Practice in Comprehensive Sexuality Education. A Global Review. UNESCO Paris; 2015.

7. Javadnoori M. Principles of education and counseling in the sex training of children and adolescents. Tehran: Jameenegar; 2016:210. [Persian]

8. Majdpour M, Parhizkar S, Mousavizadeh A, Shams MJT-e-b. Mothers' Views about Sexuality Education to their Adolescent Girls; a Qualitative Study. J TOLOO E BEHDASHT 2017;16(3):93105. [Persian]

9. Ghorbani M, Zamani-Alavijeh F, Shahry P, Zare K, Marashi T. Understanding childhood's sexual curiosity: An introduction to sexual health education and health promotion. 2015;3(3):198-210. [Persian]

10. Ceka A, Murati R. The role of parents in the education of children. Faculty of Philosophy, University of Tetova, 176 no. 53A, Tetovo, 1200 Macedonia, Faculty of Philosophy, University of Tetova, 1200 Macedonia. Journal of Education and Practice. 2016;7(5).

11. Merghati-Khoei E, Abolghasemi N, Smith TG. "Children are sexually innocent": Iranian parents' understanding of children's sexuality. Arch Sex Behav. 2014;43(3):587-95.

12. Vanderberg RH, Farkas AH, Miller E, Sucato GS, Akers AY, Borrero SB. Racial and/or ethnic differences in formal sex education and sex education by parents among young women in the United States. J Pediatr Adolesc Gynecol. 2016;29(1):69-73.

13. Kirby D. Increasing communication between parents and their children about sex. BMJ. 2008;337.

14. El-Shaieb M, Wurtele SK. Parents' plans to discuss sexuality with their young children. Am J Sex Educ. 2009;4(2):103-15.

15. Mostofi N, Garmaroudi G, Shamshiri A, Shakibazadeh E. Effect of group education on knowledge, attitude and practice of mothers of adolescent girls about sex education. Journal of School of Public Health and Institute of Public Health Research. 2016;14(3):45-59. [Persian] 
16. Opara PI, Eke GK, Tabansi PN. Perception of sexuality education amongst secondary school students in Port Harcourt, Nigeria. West Afr J Med. 2012;31(2):109-13.

17. Kim JL, Ward LM. Silence speaks volumes: Parental sexual communication among Asian American emerging adults. J Adolesc Res. 2007;22(1):3-31.

18. Lule E, Rosen JE, Singh S, Knowles JC, Behrman JR. Adolescent health programs. Disease control priorities in developing countries. 2006;2:1109-26.

19. Vakily M, Noroozi M, Yamani N. Comparing the effect of group-based and compact disk-based training on midwives' knowledge and attitude toward domestic violence in women of reproductive age. J Educ Health Promot. 2017;6:70.

20. Rindner L, Strömme G, Nordeman L, Hange D, Gunnarsson R, Rembeck G. Reducing menopausal symptoms for women during the menopause transition using group education in a primary health care setting — a randomized controlled trial. Maturitas. 2017;98:14-9.

21. Lee EM, Kweon YR. Effects of a Maternal Sexuality Education Program for Mothers of Preschoolers. J Korean Acad Nurs. 2013;43(3).

22. Navaei M, Akbari-Kamrani M, Esmaelzadeh-Saeieh S, Farid M, Tehranizadeh M. Effect of Group Counseling on Parents' Self-Efficacy, Knowledge, Attitude, and Communication Practice in Preventing Sexual Abuse of Children Aged 2-6 Years: A Randomized Controlled Clinical Trial. Int J Community Based Nurs Midwifery. 2018;6(4):285.

23. Mobredi K, Hasanpoor-Azghady SB, Azin SA, Haghani H, Farahani LA. Effect of the sexual education program on the knowledge and attitude of preschoolersâ mothers. Journal of Clinical and Diagnostic Research. 2018;12(6):JC06-9. [Persian]

24. Cheraghi F, Rostaie Z, Asgari M, Shamsaei F, Tapak L. The Effect of Training of Parental Role on Mothers' Attitude with Children Aged 1-5 Years with Respect to Children'Abuse. Iranian Journal of Health Education and Health Promotion. 2017;5(3):182-90. [Persian]

25. Khanjari S, Modabber M, Rahmati M, Haghani H. Knowledge, Attitudes and Practices among Parents of School-age Children after Child Sexual abuse Prevention Education. Iran Journal of Nursing. 2017;29(104):17-27. [Persian]

26. Hashemi Bakhshi S, Jalili Z, Mahmoudi M. The Effect of Theory-Based Educational Intervention on Mother's Skill About Sexual Care of Their Children. Journal of School of Public Health and Institute of Public Health Research. 2018;16(1):87-98. [Persian]

27. Besharat MA, Azizi K, Poursharifi H. The relationship between parenting styles and children's perfectionism in a sample of Iranian families. Procedia-Social and Behavioral Sciences. 2011;15:1276-9. [Persian]

28. Wilson EK, Dalberth BT, Koo HP, Gard JC. Parents' perspectives on talking to preteenage children about sex. Perspect Sex Reprod Health. 2010;42(1):56-63. 